\title{
Jenis-jenis Nyamuk di Daerah Kawasan Industri Sidangoli, Halmahera, dan Maluku Utara
}

\author{
MARDJAN SOEKIRNO \\ Pusat Penelitian dan Pengembangan Ekologi Kesehatan \\ Badan Iitbang Keschatan \\ Il. Percetakan Negara No. 29, Jakarta \\ (diterima Oktober 2004, disetujui April 2005)
}

\begin{abstract}
Mosquitoes Species in Industrial Area Sidangoli, Halmahera, and North Maluku. A Study about mosquitoes species in industrial area Sidangoli, Halmahcra, North Maluku was carried out from June 1993 to March 1994. Collecrions of mosquito from various habitats were done by six merhods: (1) Collections of lariae and pupae from various habitats and reared in laboratory, (2) Night man-biting collections, (3) Night animal-biting collections or resting collections around cattle shelter, (4) Morning indoor resting collections, (5) Light trap collections, (G) Space spraying collections. All mosquitoes collected were than brougth and identification to each species in the laborator. The result showed that in industrial area Sidangoli have been identified 18 species of mosquitocs, which consist of 2 species Aedes, 6 species Anopheles, 8 species Culex, and 2 species Mansonia.
\end{abstract}

KEY WORDS: Mosquito species, industrial area, anopheles, culex, mansonia.

\section{PENDAHULUAN}

Pulau Halmahera termasuk Kawasan Timur Indonesia yang mempunyai arti penting dalam pembangunan nasional, khususnya sektor transmigtasi dan industri. Kecuali itu juga mempunyai nilai penting dalam pengembangan ilmu pengetahuan, khususnya dunia binatang yang mencakup pula nyamuk, karena letaknya di daerah perbatasan antara Oriental dan Australia.

Di daerah ini belum pernah dilakukan penelitian dan pengamatan vektor dengan teratur, sehingga baik fauna Anopheles maupun vektor malarianya belum diketahui dengan pasti. Demikian pula jenis-jenis nyamuk lainnya belum diketahui dengan pasti.

Pemberantasan penyakit menular seperti malaria, filariasis, demam berdarah dengue dan lainnya yang ditularkan oleh berbagai jenis nyamuk adalah sesuatu yang cukup kompleks, karena adanya dua faktor yang saling terkait, yaitu faktor manusia dan vektor (nyamuk), yang masing-masing mempunyai permasalahan sendiri.

Upaya pemberantasan vektor yang dilakukan oleh program pemberantasan penyakit menular belum dilandasi penguasaan seluk-beluk vektor yang tepat dan benar. Untuk menyelesaikan masalah pemberantasan penyakit menular di 
Halmahera perlu dilakukan penelitian vektor yang berperan. Penelitian yang dilakukan diarahkan untuk pemetaan tempat perindukan vektor yang potensial, mengetahui fauna nyamuk dan kemampuan menularkan penyakit tertentu oleh vektor serta berbagai jenis nyamuk lainnya.

Dalam makalah ini dikemukakan hasil penelitian jenis-jenis nyamuk yang ditemukan di daerah kawasan industri Sidangoli, Halmahera. Semoga bermanfaat bagi penentuan program pemberantasan penyakit menular di Halmahera, untuk mencegah terjadinya transmisi vang lebih luas.

\section{BAHAN DAN METODE}

\section{Daerah Penelitian}

Penelitian ini dilakukan di daerah kawasan industri Sidangoli yang terletak di pantai Pulau Halmahera, termasuk wilayah Maluku Utara, Kawasan Timur Indonesia selama sembilan bulan (Juni 1993 sampai dengan Maret 1994).

Wilayah Maluku Ltara terletak di antara Samudera Pasifik, Laut Seram, Laut Halmahera dan Laut Maluku; di antara $124^{\circ}-129^{\circ} \mathrm{BT}$ dan $3^{\circ} \mathrm{LL}^{\circ}-3^{\circ} \mathrm{LS}$. Luas wilayah $103.789 \mathrm{Km}^{2}$, terdiri atas $78 \%$ lautan dan $22 \%$ daratan. Jumlah penduduk (tahun 1990) 560.241 jiwa, tahun 1992 tercatat 561.354 jiwa. Administrasi pemerintahan meliputi 21 kecamatan, 1 kota administratif, 23 kelurahan dan 569 desa. Mata pencaharian terdiri atas $62,20 \%$ petani, $14,23 \%$ ne- layan, $6,1 \%$ perdagangan, $4,07 \%$ pegawai negeri, $1,22 \%$ industri kecil, $0,99 \%$ usaha jasa dan $11,18 \%$ campuran. Sebagian besar penduduk beragama Islam $(67,5 \%)$, sedangkan lainnya Kristen Protestan 31,05\%, Kristen Katolik $1,41 \%$, Hindu $0,01 \%$ dan Budha $0,03 \%$ (Albaar, 1992).

\section{Pengumpulan Data}

Dalam penelitian ini dilakukan pengamatan entomologi yang meliputi pengamatan jentik/larva dan pengamatan nyamuk dewasa dari berbagai macam habitat di dacrah kawasan industri Sidangoli. Pengamatan tersebut menggunakan metode baku dari WHO.

Pengamatan jentik, diadakan pencidukan pada genangan air baik genangan air secara alami maupun buatan manusia. Jentik dan pupa yang terciduk dikumpulkan dan dipelihara di laboratorium sehingga menjadi nyamuk dewasa dan diidentifikasi menurut spesiesnya. Pengamatan dilakukan olch peneliti dan teknisi. Frekuensi pengamatan dilakukan dua mingguan.

Pengamatan nyamuk dewasa diadakan pada pagi dan malam hari dengan berbagai cara, yairu:

1. Diadakan penangkapan nyamuk pada malam hari dengan umpan orang; hal ini dilakukan untuk mengetahui jenis/spesies nyamuk apa saja yang suka menghisap darah manusia.

2. Diadakan penangkapan nyamuk malam hati dengan umpan binatang atau di sekitar kandang sapi; hal ini dilaku- 
kan untuk mengetahui spesies nyamuk apa saja yang suka menghisap darah binatang atau ternak.

3. Diadakan penangkapan nyamuk pagi hari di dalam rumah penduduk setempat dan di alam luar; hal ini dilakukan untuk mengetahui spesies nyamuk apa saja yang pada siang hari bersembunyi di dalam rumah dan di luar rumah.

4. Diadakan penangkapan nyamuk malam hari dengan perangkap lampu (light trap); hal ini dilakukan untuk mengetahui spesies nyamuk apa saja yang tertarik pada sinar.

5. Diadakan penangkapan nyamuk siang hari dengan Space Spraying (penyemprotan di dalam kamar dengan insektisida tertentu); hal ini dilakukan untuk mengetahui spesies nyamuk apa saja yang pada siang hari berada di dalam rumah penduduk setempat.

Semua nyamuk yang didapat dilakukan pemeriksaan di laboratorium. Identifikasi nyamuk sampai dengan spesies dilakukan dengan menggunakan kunci determinasi yang disusun olch Ramalingam (1974), Reid (1968), O'Connor dan Soepanto (1979), dan Das et al. (1990).

\section{HASIL DAN PEMBAHASAN}

Hasil pemeliharaan larva dan pupa yang dikumpulkan dari daerah kawasan industri Sidangoli menunjukkan bahwa dari banyak tempat berair yang diperiksa didapatkan 4 spesies nyamuk Anopheles, yaitu An. farauti, An. subpictus, $A n$. tesselatus dan $A n$. vagus. Selain nyamuk
Anopbeles ditemukan juga 7 spesies nyamuk Culex, yaitu Cx. fustanus, $C x$ gelidus, $C x$ balifaxi, $C x$. pallidothorax, $C x$. quinquefasciatus, $C x$ : tritaenioriynthes dan Cx. vishnui (Tabel 1).

Hasil penangkapan nyamuk pagi hari di dalam rumah penduduk setempat (indoor) dan penangkapan nyamuk pagi hari di alam luar (outdoor) tidak didapatkan nyamuk Anopheles, tetapi nyamuk Culex cukup banyak jenisnya yang terdiri atas $C x$, fuscanus, $C x$. gelidus, $C x$ : pallidotborax, $C_{x}$ quinquefascialus, $C_{x}$ : tritaeniorbynchus dan C.x vishnui; sedangkan nyamuk Aedes dan Mansonia masingmasing didapatkan satu spesies, yaitu $A e$. aegypti dan Ma. tuiformis (Tabel 1).

Hasil penangkapan nyamuk dengan Space Spraying menunjukkan bah-wa di dacrah kawasan industri Sidangoli didapatkan nyamuk Anopheles nagus, sedangkan nyamuk Culex didapatkan 3 spesies, yaitu $C x$ mimetizss, $C x$. quinquefastiatus dan $C x$ : tritaenior-bynchus. Nyamuk Ledes ditemukan satu spesies, yaitu Ae. Aegyti (Tabel 1).

Hasil penangkapan nyamuk dengan umpan orang di daerah kawasan industri Sidangoli tidak didapatkan Anopheles. Spesies nyamuk lainnya yaitu Ae. aegypti dan Ae. albopittur; nyamuk Mansonia terdiri atas Ma. annulifera dan Ma. uniformir; sedangkan nyamuk Cutex terdiri atas $C x$ gelidus, $C x$ : pallidothorax, Cx. quinquefasciatus dan $C x$. Tritaeniorlynn. chus (Tabel 2).

Hasil penangkapan nyamuk dengan umpan binatang (sapi) di dacrah kawasan industri Sidangoli juga disajikan 
Tabel 1. Hasil penangkapan nyamuk dengan koleksi larva dan pupa (KLP). menangkap pagi hari (Morning Indoor Resting - MIR) dan penyemprotan insektisida di dalam kamar (Space Spraying - SS) di daerah kawasan industri Sidangoli, Halmahera, Maluku Utara.

\begin{tabular}{|c|c|c|c|c|c|c|c|}
\hline \multirow{3}{*}{ No. } & \multirow{3}{*}{ Spesies nyamuk } & \multicolumn{6}{|c|}{ Cara penangkapan } \\
\hline & & \multicolumn{2}{|c|}{ KLP } & \multicolumn{2}{|c|}{ MIR } & \multicolumn{2}{|c|}{ SS } \\
\hline & & Betina & Jantan & Betina & Jantan & Betina & Jantan \\
\hline 1. & Aedes sp. & 377 & 129 & 7 & 11 & 93 & 126 \\
\hline 2. & Anopheles farauti & 4 & 0 & 0 & 0 & 0 & 0 \\
\hline 3. & An. subpictus & 8 & 4 & 0 & 0 & 0 & 0 \\
\hline 4. & An. tesselatus & 48 & 48 & 0 & 0 & 0 & 0 \\
\hline 5. & An, vagus & 22 & 16 & 0 & 0 & 2 & 4 \\
\hline 6. & Culex fuscanus & 66 & 52 & 6 & 6 & 0 & 0 \\
\hline 7. & Cx. gelidus & 90 & 64 & 12 & 6 & 0 & 0 \\
\hline 8 & Cx. halifaxi & 0 & 2 & 0 & 0 & 0 & 0 \\
\hline 9. & Cx. mimeticus & 0 & 0 & 0 & 0 & 5 & 11 \\
\hline 10. & Cx. pallidothorax & 4 & 2 & 10 & 3 & 0 & 0 \\
\hline 11. & Cx. quinquefasciatus & 4 & 4 & 88 & 103 & 78 & 154 \\
\hline 12. & $\mathrm{Cx}$, tritaeniorhynchus & 356 & 334 & 6 & 7 & 15 & 29 \\
\hline 13. & Cx. vishnui & 10 & 18 & 2 & 0 & 0 & 0 \\
\hline \multirow[t]{2}{*}{14.} & Mansonia unifomis & 0 & 0 & 1 & 0 & 0 & 0 \\
\hline & Jumlah & 989 & 673 & 132 & 136 & 193 & 324 \\
\hline
\end{tabular}

Tabel 2. Hasil penangkapan nyamuk dengan umpan orang (Night Landing Collection - NLC). umpan binatang (KD) dan perangkap lampu (Light Trap - LT) di daerah kawasan industri Sidangoli, Halmahera, Maluku Utara.

\begin{tabular}{lccc}
\hline \multirow{2}{*}{ No. Spesies nyamuk } & \multicolumn{3}{c}{ Cara penangkapan } \\
\cline { 2 - 4 } & NLC & KD & LT \\
\hline 1. Aedes sp. & 36 & 105 & 12 \\
2. Anopheles kochi & - & 8 & 5 \\
3. An. maculatus & - & 3 & 2 \\
4. An. subpictus & - & 29 & 8 \\
5. An. tesselatus & - & 5 & - \\
5. An. vagus & - & 14 & 3 \\
7. Cujox fuscanus & - & 31 & - \\
8. Cx. gelidus & 27 & 192 & 36 \\
9. Cx. pallidothorax & 640 & 836 & - \\
10. Cx. quinquefasciatus & 144 & 317 & 24 \\
11. Cx. tritaeniorhynchus & - & 12 & 7 \\
12. CX. vishnui & 3 & - & - \\
13. Mansonia annulifera & 12 & 6 & - \\
14. Ma. Uniformis & 874 & 1.558 & 116 \\
\hline
\end{tabular}

dalam Tabel 2. Pada tabel tersebut terlihat bahwa di daerah kawasan industri Sidangoli didapatkan 5 spesies Anopheles, yaitu An. kochi, An. maculatus, An. subpictus, An. tesselatus dan An. vagus. Dari hasil yang didapat menunjukkan bahwa selain nyamuk Anoplseles didapatkan juga nyamuk Aedes, Culex dan Mansonia. Nyamuk Aedes terdiri atas Ae. aegypti dan Ae. albopitus; nyamuk Culex terdiri atas 5 spesies, yaitu $C x$ : ftritants, $C x:$ gelidus, CX. quinquefas-ialtss, Cx. tritaeniorlynchus dan Cx: vishnti; sedangkan nyamuk Mansonia terdiri atas Ma. tuiformis.

Pemakaian perangkap lampu (light (rap) untuk menangkap nyamuk di daerah kawasan industri Sidangoli dida- 
patkan 4 spesies Anopheles, yaitu An. kochi, An. maculatus, An. subpictus dan $A n$. vagus. Selain nyamuk Anopbeles didapatkan juga berbagai spesies Aedes dan Culex. Nyamuk Aedes terdiri atas Ae. aegyti dan Ae. albopittus; sedangkan nyamuk $C$ ulex terdiri atas 4 spesies, yaitu $C x$ ge/idus, $C x$. quinquefasciatus, $C x$. tritaeniorbynchus dan $C x$ visbnut.

Dari hasil penangkapan nyamuk dengan 6 (enam) macam cara di daerah kawasan industri Sidangoli, ternyata cara penangkapan nyamuk dengan umpan binatang mendapatkan jumlah spesies yang terbanyak, yaitu 13 spesies, terdiri atas 2 spesies Aedes, 5 spesies Anopheles, 5 spesies Culex dan 1 spesies Mansonia. Sedangkan cara penangkap-an nyamuk dengan Space Spraying mendapatkan jumlah spesies nyamuk yang paling sedikit, yaitu 5 spesies, terdiri atas $A$ e. aegypti, An. vagus, $C \times$ mimeticus, $C x$, quinquefasiza Ius dan Cx. tritaeniorbynchus. Urutan kedua terbanyak jumlah spesies yang didapat ditempati oleh cara penangkapan nyamuk dengan koleksi larva dan pupa dari berbagai habitat, yaitu didapatkan 12 spesies nyamuk, terdiri atas 2 spesies Aeder, 4 spesies Anopheles, 6 spesies Culex: Urutan ketiga terbanyak jumlah spesies yang didapat ditempati oleh cara penangkapan nyamuk dengan perangkap lampu (light trap), yaitu didapatkan 10 spesies nyamuk, terdiri atas 4 spesies Anopheles, 4 spesies Culex dan 2 spesies Aedes. Lrutan keempat dan kelima masing-masing dengan 9 spesies didapatkan dari cara penangkapan nyamuk pagi hari di dalam rumah penduduk dan di alam luar serta 8 spesies didapatkan dari cara penangkapan nyamuk dengan umpan orang (Tabel 3).

Pada Tabel 3 tersebut di atas dapat dilihat bahwa dari hasil pengumpulan larva dan pupa tidak didapatkan nyamuk Mansonia, sedangkan dari hasil penangkapan nyamuk pagi hari tidak didapatkan nyamuk Anopbeles, sehingga dapat diketahui bahwa hanya nyamuk Culex yang dapat ditangkap dengan 6 macam cara yang dipergunakan dalam penelitian ini. Dari 8 spesies Culex yang didapatkan dalam penelitian ini hanya 2 spesies yang dapat ditangkap dengan semua cara yang dipergunakan, yaitu $C x$. quinquefas-ciatus dan Cx. tritaeniorbynibus.

Dari binatang yang ada di Halmahera, khususnya di daerah kawasan industri Sidangoli, sapi merupakan binatang yang banyak dipelihara penduduk, karena sangat menguntungkan, yairu membantu pekerjaan di sawah/ladang, transportasi dan menghasilkan pupuk kandang. Selain itu sapi dapat dipakai sebagai barier, karena merupakan sumber darah yang baik bagi berbagai spesies nyamuk. Selain daya tarik yang cukup kuat, jumlahnya juga cukup banyak, sehingga sangat mengurangi jumlah nyamuk yang menghisap darah manusia.

Hasil penangkapan nyamuk dengan perangkap lampu di dacrah kawasan industri Sidangoli didaparkan 116 ekor nyamuk. Jumlah ini ternyata paling kecil dibandingkan dengan hasil penangkapan dengan 5 cara yang lain, tetapi jumlah spesies yang didapatkan cukup 
Tabel 3. Hasil penangkapan nyamuk dengan 6 (enam) macam cara (KLP $=$ Koleksi Larva dan Pupa: MIR = "Morning Indoor Resting"; NLC = "Night Landing Collection"; $K D=$ sekitar Kandang; $L T$ = "Light Trap" perangkap lampu; $S S=$ "Space Spraying") di daerah kawasan industri Sidangoli, Halmahera, Maluku Utara.

\begin{tabular}{|c|c|c|c|c|c|c|c|}
\hline No. & Spesies nyamuk & KLP & MIR & NLC & $\mathrm{KD}$ & LT & SS \\
\hline 1. & Aedes aegypti & + & + & + & + & - & + \\
\hline 2. & Ae albopictus & + & + & + & + & + & $\cdot$ \\
\hline 3. & Anopheles farauti & + & - & - & $\cdot$ & $\cdot$ & - \\
\hline 4. & An kochi & - & - & $\cdot$ & + & + & - \\
\hline 5. & An. maculatus & - & - & - & + & + & - \\
\hline 6. & An. subpictus & + & - & - & + & + & $\cdot$ \\
\hline 7. & An, tesselatus & + & - & - & + & $\cdot$ & - \\
\hline 8. & An. vagus & + & - & $\cdot$ & + & - & + \\
\hline 9. & Culex fuscanus & + & + & - & + & - & - \\
\hline 10. & Cx, gefidus & + & + & + & + & + & - \\
\hline 11. & Cx. halifaxi & + & - & + & - & - & $\cdot$ \\
\hline 12. & Cx. mimeticus & - & - & - & $\cdot$ & - & + \\
\hline 13 & Cx. pallidothorax & + & + & + & - & - & - \\
\hline 14. & Cx. quinquefasciatus & + & + & + & + & + & + \\
\hline 15. & Cx. tritaeniornynchus & + & + & + & + & + & + \\
\hline 16. & Cx. vishnui & + & + & - & + & + & - \\
\hline 17. & Mansonia annulifera & - & - & + & - & - & - \\
\hline 18. & Ma. uniformis & - & + & + & + & - & - \\
\hline
\end{tabular}

banyak, yaitu mencapai 10 spesies nyamuk. Untuk lebih mengefektifkan penangkapan nyamuk dengan perangkap lampu, perlu dicoba dengan menaruh $d r y$ ice di bawah perangkap lampu. Dy lie mempunyai daya tarik cukup kuat terhadap nyamuk, sehingga dengan menaruh dy ite di bawah perangkap lampu, daya tarik perangkap lampu terhadap nyamuk diperkuat, dengan cara demikian diharapkan akan meningkatkan jumlah dan jenis (spesies) nyamuk yang datang dan masuk ke dalam perangkap lampu.

\section{KESIMPULAN}

Dari uraian tersebut di atas dapat disimpulkan bahwa telah didapatkan sejumlah 18 spesies nyamuk yang ditangkap dengan 6 macam cara di daerah kawasan industri Sidangoli yang berada di Halmahera, Maluku Ltara, terdiri atas 2 spesics Aedes, 6 spesies Anopheles, 8 spesies Culex dan 2 spesies Mansonia. Ke-18 spesies nyamuk yang didapatkan di daerah kawasan industri Sidangoli, Halmahera, Maluku Ltara adalah sebagai berikur: Aedes aegypti, At. allopituts, $A n$. farauti, An. kochi, An. maculatur, $A n$. subpictus, An. tesselatus, An. vagus, Culex frtcanus, $C x$ gelidus, $C x$ balifaxi, $C x$. mimeticus, $C x:$ pallidotho-rax, $C x$ quinquefasciatus, $C x$ : tritae-niorlynchus, $C x$. visbuni, Mansomia annulifera, dan Ma. uniformis.

\section{DAFTAR PUSTAKA}

Albaar, S. 1992. Laporan Tahunan Dinas Kescharan Kabupaten Maluku Lrara di Ternate.

Annonymous. 1975. Manual on Practical Entomology in Malaria. WHO Publication, Geneva, 13: Part II. $55 \mathrm{p}$.

Das, B.P., R. Rajagopal, and J. Akivama. 1990. Pictorial Key to Spesies of Indian Anopheline Mlosquitoes. Zoology J. of Pure and Applied Zoology), 2(3):131-162. 
O'Connor, C.T. and A. Soepanto. 1979. Kunci Bergambar untuk Anopheles dari Indonesia. Dit. Jen. P3M Dep. Kes. 40 p.

Ramalingam, S. 1974. A Brief Mosquito Survey of Java. WHO document. WHO/BC/ 74.504. $66 \mathrm{p}$.
Reid, A. 1968. Anopleles Mosquito of Malaya and Bomeo, lnst. Med. Res. Mfalayat, No. 31:520. 